\title{
HOMEOWNERS' PERCEPTIONS OF PROPERTY-LEVEL FLOOD RISK ADAPTATION (PLFRA) MEASURES: THE CASE OF THE SUMMER 2007 FLOOD EVENT IN ENGLAND
}

\author{
R. JOSEPH ${ }^{1,2}$, D. PROVERBS ${ }^{1} \&$ J. LAMOND ${ }^{1}$ \\ ${ }^{1}$ Faculty of Environment and Technology, University of the West of England, United Kingdom. \\ ${ }^{2}$ Cunningham Lindsey, United Kingdom.
}

\begin{abstract}
Flood events have far-reaching consequences, not only in economic or financial terms but also in social and health-related impacts. There is a growing body of research that suggests that property-level flood risk adaptation (PLFRA) measures have the potential to benefit homeowners by reducing the impact of flooding on households. Emphasis has, therefore, been placed on the implementation of PLFRA measures, and yet despite this, the take-up among the at-risk residents in England is low. One of the reasons identified in the literature is that homeowners do not clearly recognise the benefits of the measures. This research uses a survey of households affected by the summer 2007 flood event in England to investigate the perception of homeowners in connection with the benefits of PLFRA measures. The results highlight that there is a consensus among respondents that implementing adaptation measures has the potential to reduce health-related flood impacts such as worrying, stress and strain between families. However, there was a high level of uncertainty with regard to potential financial benefits from investing in adaptation measures, in the form of premium reduction by insurers. It was evident from the analysis that knowledge of the frequency of future flood events and expected flood damage rated highly among the factors perceived by homeowners to influence the uptake of PLFRA measures. Furthermore, the results show that there is a wide range of opinion among the respondents as to who is responsible for protecting homes against flood risk. For instance, the government flood protection scheme has the potential to provide a confusing message to floodplain residents as to whose responsibility it is to protect properties against flood risk. It is, therefore, recommended that at-risk population should be made aware of the limits of the responsibilities of other stakeholders in the domain of flood risk management at household levels. However, it is anticipated that the introduction of the new UK flood insurance scheme, Flood Re, may help to bring more clarity. There is a need to increase the motivation of homeowners to invest in PLFRA measures, which could be achieved through a range of actions, including the provision of subsidies and incentives, which would help in promoting more sustainable behaviour. Keywords: intangible impacts, inter-rater indices, property-level flood adaptation, resilience measures, resistance measures
\end{abstract}

\section{INTRODUCTION}

The impact of flood events on communities is far reaching. Not only do floods cause significant direct and indirect economic or financial losses, but they also lead to social and health-related problems. There are an estimated 5.2 million properties in England and Wales located in flood-risk areas, amounting to one in six properties [1]. According to the Department for Environment Food and Rural Affairs (DEFRA) [2], this figure is likely to rise further through the effects of climate change leading to more frequent extreme weather events, and also if properties continue to be built on floodplains [3].

Budget limitations and other competing priorities restrain the number of community-level flood defence projects that the UK Government can finance [1]. Therefore, alternative flood risk management approaches have to be enacted. According to Neal et al. [4], there has been growing interest in what are termed non-structural or 'soft' engineering solutions to flood risk 
management. Furthermore, Evans et al. [5] stressed the need for a conceptual shift in which management of flood risk relies less on government intervention and more on an acceptance of individual responsibility. This approach has implications for homeowners to accept some responsibility for managing flood risk at property level. The adoption of property-level flood risk adaptation (PLFRA) measures involves a process in which physical improvements are made to properties to either prevent flood water from entering (resistance measures) or to minimise the damage when flood water enters (resilience measures) [6,7].

Research has shown that temporary resistant measures such as flood boards can reduce the average cost of flood damage by 50-100\% [8]. Conversely, permanent measures in the form of automatic flood barriers are found to be able to reduce the average cost of flood damage in an individual flood event by $65-100 \%$ [8]. The cost of resistance measures ranges from $£ 6,000$ to $£ 11,000$, depending on property type and anticipated flood level [8]. However, due to their higher cost, implementation of full resistance measures may only make economic sense for premises in areas of very high flood frequency, or where the potential cost of flood damage is high. Most of the resistance measures can be installed at any time, with no subsequent extra cost implications. In situations where the installation of flood resistance measures is not practicable or viable, for instance, terraced properties flood damage can still be mitigated by adopting resilience measures.

Building resilience in the context of this paper is the ability of a property/building to withstand and recover from the effects of flooding without causing serious damage to the fabric of the property/building. Measures such as the installation of concrete floors, impermeable wall and floor finishes, and water resistance rendering are examples of resilience measures. Research has shown that the cost of implementing full resilience measures ranges from $£ 12,000$ to $£ 28,000$ [7-9], depending on property type, anticipated flood depth and floor construction. Due to the high cost involved in implementing resilience measures, they are more economically viable when installed during reinstatement of a building after it has been flooded or as part of planned renovations. The effectiveness of resilience measures is dependent on the anticipated flood depth and duration. It has been suggested that a full flood risk assessment should be carried out before investing in resilience measures [10,11]. These measures allow for faster reinstatement of properties following a flood event, thereby hasting the recovery process. Mark [12] argues that measures that minimise population displacement and favour an early return of victims to routine activities of daily living are known to lessen the adverse impact of flooding. In recent years, investing in resistance and/or resilience measures when reinstating flood damaged properties has received greater attention [13], and the onus of doing this has shifted to individual homeowners [14]. The UK Government's Draft Flood and Water Management Bill [15], which sets out the government's policy on water management, also contains provision about the management of risks in connection with flooding and coastal erosion. It was stated in the Bill that resilient repair is vital, and thus, a number of possible avenues for encouraging resilient repair were proposed, including a possible revision of the Building Regulations in England and Wales [15]. However, for some homeowners, the installation of resilience or resistance measures might be resisted due to various reasons such as daily reminders of the flood hazard and signalling of flood risk to potential purchasers, which could lead to a reduce market value of the property. Conversely, the potential flood risk cannot be ignored despite the perception of negative stigma which can result from the presence of these measures in a property, the need for peace of mind, which may be achieved by investing in resistance and resilience measures could be the primary reason for taking up the measures [16]. Proverbs and Lamond [17] asserted that the likelihood 
of taking action against flood risk is a function of desire and ability to act. This means that awareness of the risk of flooding and ownership of the risk are part of the desire to do something to reduce the risk; similarly, awareness of solutions and belief in their ability to either prevent flooding or to reduce damage caused by inundation to a property are both part of the ability to act, by way of installing flood protection measures.

Engaging floodplain residents in the process of flood risk management is an important factor in realising the aim of emerging flood risk management strategies in the UK. Floodplain residents must be encouraged to take actions ranging from registering for flood warnings to installing their own defence and alarm systems [18]. For example, the Environment Agency has instituted a public awareness programme and undertaken extensive consultations on adaptation measures; whilst in 2007, the UK Government, through the DEFRA launched a pilot grant scheme that provided over $£ 5$ million funding for property-level flood protection surveys and measures in some part of England. Despite this, Wallingford [19] concluded that the take-up of flood adaptation measures remains low among floodplain residents. A review of extant literature revealed that the UK is not alone in this situation as adoption of flood mitigation measures is low in many countries [11,20]. It is hypothesised by Joseph et al. [21] that this low take-up is due in part to the fact that homeowners are not aware of or do not value the intangible benefits of investing in PLFRA measures. Understanding intangible benefits is especially relevant when a homeowner is fully insured and the majority of the tangible costs will be covered by their insurers, thereby leaving the homeowners to deal with the intangibles. The main aim of this research was to investigate homeowners' perception of PLFRA measures. Consequently, the research sought to answer the research question 'what factors might influence floodplain residents' decisions on PLFRA measures.

\section{THEORETICAL BENEFITS OF PLFRA MEASURES}

With regard to insured households, the benefits of investing in PLFRA measures can be categorised into two main strands, these are; financial benefits to insurance companies and intangible benefits to households [21]. However, uninsured households have the potential to benefit both in financial and social terms if they invest in PLFRA measures. Studies have shown that for properties that flood more than once in 10 years, the financial benefits outweigh the up-front investment by a factor of between 5 and 10 [8].

In the UK, when an insured domestic property suffers flood damage, the insurance provider is obliged to replace damaged contents and repair or renew the building fabric. In addition to these, any other costs incurred such as expenses for alternative accommodation are usually reimbursed (depending on policy terms) by insurance providers for fully insured homeowners. However, if a homeowner had already invested in PLFRA measures, the reduction in claim cost following subsequent flooding would mean that the insurer would spend less money during reinstatement process. Thus, for insurers, the adoption of PLFRA measures by their customers has the potential to reduce the claim spend assuming such properties suffer subsequent flood damage [7].

The benefits to insured homeowners of adopting PLFRA measures in most cases are difficult to encapsulate in monetary terms [7]. However, it has been suggested that the adoption of the measures could be taken into consideration by insurers when quoting for flood insurance [22], thereby making it possible to obtain insurance cover at an affordable price or to lead to a reduction in insurance premiums, although, this can only be effected by insurers if premiums are charged based on risk. Other non-financial benefits to households are reduction/elimination of some of the intangible impacts of flooding such as deterioration of physical and mental 
health [23], worrying about future flooding strains between families, loss of community spirit and time spent in alternative accommodation [24]. Different authors have demonstrated that adopting resistance and resilience property adaptation measures are beneficial in financial terms to different stakeholders in the flood risk management domain $[7,8]$.

\section{RESEARCH METHODOLOGY}

\subsection{The summer 2007 flood event}

The summer 2007 flood event in England was selected as a means of investigating homeowners' perception of the PLFRA measures. This event brought about widespread flooding, which affected much of the UK during June and July 2007, and it followed the wettest-ever May since national records began in 1766 [18]. Met Office records show that an average of $414 \mathrm{~mm}$ of rain fell across England and Wales; this was well over double usual levels for May [25]. According to Neal et al. [4], the estimated average frequency of occurrence (return period) of this high total rain volume is over 200 years.

The 2007 flood event affected over 55,000 properties both residential and commercial $[18,26]$. Estimates made after the floods put the total losses at about $£ 4$ billion [27], of which insurable losses were about $£ 3$ billion [9]. Around 7,000 people were rescued from the flood waters by the emergency services and 13 people tragically lost their lives [27]. Tens of thousands of people were rendered homeless, and some businesses were put out of action for many months.

Several locations that were flooded during the 2007 flood were selected based on the need to represent the widest possible variation both geographical and flood typology while retaining minimum numbers of properties within each selected site. To that end, only sites with greater than 50 affected properties were considered. The selected sites and their main features are summarised in Table 1 . The types of reported flooding were also given consideration, the reported sites experienced river flooding and surface water flooding due to extensive rainfall.

\subsection{Data collection and analysis}

A postal questionnaire survey was employed to collect information from homeowners who experienced flood damage to their buildings. Homeowners were chosen because they are responsible for taking decisions on investments in adaptation measures and, therefore, are in the best position to answer the research questions. Gray [28] described the questionnaire survey as a research tool through which respondents are asked to respond to the same set of questions, the responses are then analysed and inferences drawn from the analysis; this can be used to inform people and change or update policy.

The questionnaire template was developed drawing from existing studies on the topic under investigation, including previous works of the authors $[7,9,21]$. The questionnaire was piloted among homeowners who were not part of the main respondent sample. The feedback received from the pilot survey contained no indication from the respondents that any of the questions or part of the questionnaire was difficult to understand. This demonstrated that the wording of the questions and the flow of the questionnaire were logical and appropriate. It also demonstrated that the respondents were familiar with the terms used and the subject under investigation. Overall, the pilot survey indicated that the questionnaire was suitable to be administered in a larger survey. 
Table 1: Selected location for empirical analysis.

\begin{tabular}{llc}
\hline Location/region & Sources & No. of properties sampled \\
\hline Barnsley/Yorkshire & River flooding & 90 \\
Beverley/Yorkshire & Surface water flooding & 106 \\
Cheltenham/South West & River flooding & 143 \\
Chesterfield/East Midlands & River flooding & 84 \\
Doncaster/Yorkshire & Surface water flooding & 230 \\
Evesham/West Midlands & River flooding & 52 \\
Gloucester/South West & River flooding & 171 \\
Grimsby/Yorkshire & Surface water flooding & 121 \\
Hull/Yorkshire & Surface water flooding & 124 \\
Pontefract/Yorkshire & River flooding & 57 \\
Retford/East Midlands & River flooding & 54 \\
Rotherham/Yorkshire & River flooding & 87 \\
Sheffield/Yorkshire & River flooding & 204 \\
Swindon/South West & River flooding & 116 \\
Tewkesbury/South West & River flooding & 183 \\
Thatcham/South East & River flooding & 418 \\
\hline
\end{tabular}

The survey template covered a range of issues such as whether respondents made use of the opportunity of the 2007 flood event to adapt their properties to potential future flood risk; whether the flood event was the first experience or there were earlier experiences of flood damage to their properties; whether they had experienced flood damage to their properties after 2007; the extent to which respondents agreed to statements on the benefits of adaptation measures were included in the survey template. This includes 'adapting property to flood risk can reduce health effect of flooding'. Data on other factors, which can influence decisions on take-up of adaptation measures, such as affordability, responsibility, knowledge of expected flood damage and flood frequencies were also collected via the survey template.

The self-administered postal option was adopted for the research. This method was selected in order to minimise cost since it has been established by Dillman [29] that the costs of a postal questionnaire are generally lower than face-to-face or telephone interviews. Whilst postal questionnaire surveys are synonymous with low response rates [30,31], it was decided that this method was suitable for the research due to the nature of information required which in most cases would require respondents to consider previous experience before they provide answers to some of the questions. It was, therefore, expected that adopting the postal method would increase quality of responses, particularly as it allows respondents to complete the questionnaires at their leisure, compared with face-to-face interviews or telephone interviews, which may not allow respondents sufficient time to consider answers.

In total, 2309 questionnaires were distributed. From this sample, 280 completed questionnaires were received; a response rate of $12.1 \%$. This compared to the standard response rate norm for postal questionnaire; indeed, low response rates in the region of $14.7 \%$ [32] have been described as the norm for comprehensive questionnaires. Others such as Samwinga [33] reported a response rate of $11 \%$ in his flood-related research; Sutrisna [34] reported a response 
rate of $8.8 \%$. Thus, owing to the sensitive nature of the research, a response rate of $12 \%$ can be considered adequate and valid for the purposes of analysis.

\section{FINDINGS}

\subsection{Level of implementation of PLFRA measures among respondents}

Table 2 shows the percentage of respondents who had implemented at least one form of adaptation measure. Non-structural measures such as registering for flood warning, moving high value items and relocating kitchen to upper floors had been implemented by $33 \%, 46 \%$ and $1 \%$, respectively. Furthermore, the results show that more people had already implemented one form of resilience measures compared with the percentage of people who had implemented resistance measures. This can be linked to the fact that some of the respondents took the opportunity of the 2007 flood event to adapt their properties; some of the resilience measure could have been implemented as part of the insurance reinstatement work without huge contribution from homeowners. Thirty percent of respondents had actually replaced timber

Table 2: Percentage of respondents who had implemented one form of adaptation measures.

Percentage of sample who had implemented PLFRA measures

PLFRA measures implemented following 2007 flood event

Non-structural measures

Registered for flood warnings

Moved high value items to upper floors

Relocated kitchen to upper floor

Resistance measures

Sandbags

Airbrick and vent covers

Waterproofing external walls

Non-return value

Automatic airbrick and vent

Doors and window guards

Automatic doors and window guards

Silicone around openings

Resilience measures

Replacing timber floor with concrete floor $\quad 30$

Using floor tile instead of carpet $\quad 25$

Using water resistant plaster $\quad 12$

Raising electrical socket above flood level $\quad 24$

$\begin{array}{lr}\text { Moving gas and electric meter above flood level } & 18\end{array}$

Tanking ground floor and basement $\quad 4$

Replacing kitchen with plastic unit 4

Replacing kitchen with stainless steel units $\quad 5$ 
floors with concrete, and $25 \%$ decided to replace carpet floor finish with tiles, which is more resilient to flood damage.

Surprisingly, minority of the respondents decided to raise electrical sockets and service meters above flood level, despite the fact that this in most cases may be cost neutral especially if the incoming electricity supply is dropped down from the ceiling [9]. One of the reasons why respondents may not want to raise electrical socket above flood level could be due to aesthetic or signalling of flood risk to potential buyers as noted by Lamond and Proverbs [11]. With regard to resistance measures, $16 \%$ of respondents had installed airbrick and vent covers, while $15 \%$ stated that they had used silicone around openings such as cable or pipe openings. The main reason for this could be attributed to the fact that these measures are not expensive, thereby affordable to respondents. It is necessary to state that the results presented here should be interpreted with caution because the survey only targeted those who had previous flood experience. Responses from those homeowners who had no previous experience of flood damage to their properties were found to be lower in the result of research carried out by Whitmarsh [35].

Comparing the results presented in Table 2 with previous reported studies shows that there has been some increase in the level of uptake of PLFRA measures. For instance in 2004, 60\% of at-risk populations in England and Wales claimed to be aware that they lived in a flood risk area and only $17 \%$ confirmed that they knew how to protect their homes against flooding. By 2005 , the number of at-risk population who had taken any action to protect their homes against flood risk was 39\% [36]. The report of the evaluation of DEFRA pilot grant scheme [37] shows that $93 \%$ of at-risk population were offered and accepted the installation of one form of flood protection measures in their properties. The reason for the high percentage of at-risk population who participated in the scheme can be attributed to the fact that none of the beneficiaries contributed financially towards the installation of the measures. Similarly, in the case of respondents in this study who had no financial support/grant from government and are still able to implement some level of resistance/resilience measures, they are seen to be more aware and receptive to measures than those that are at risk on average, thereby it can be inferred that their flood experiences, to some extent, played a part in their level of receptiveness to the measures.

\subsection{Homeowner's perception of benefits of PLFRA measures}

Data on the potential benefits of PLFRA measures were collected using a five-point Likert scale ranging from 'strongly agree to strongly disagree'. A weighting was assigned to each level of agreement, where 'strongly agree' $=5$, 'agree' $=4$, 'uncertain' $=3$, 'disagree' $=2$ and 'strongly disagree' $=1$. An inter-rater agreement test was carried out on the responses received.

\subsubsection{Inter-rater agreement test}

Inter-rater agreement represents the extent to which different respondents tend to make exactly the same judgements about the rated subject [38]. When judgements about a subject are made on a numerical scale, inter-rater agreement means that the respondents assigned exactly the same values when rating the same subject [39]. An inter-rater agreement estimates whether the response from one respondent is "similar" to the responses of others rating the same subject, thus reflecting the degree of "agreement" among the respondents. An inter-rater agreement test is often used in organisational multi-level research [40] and it has been applied in other related studies such as Tuuli [41], Anvuur and Kumaraswamy [42] and Manu [39]. 


\subsubsection{Potential benefits of PLFRA measures}

An inter-rater agreement test was conducted using the single-item inter-rater agreement index (rWG) by James et al. [43]. The presence of significant agreement means that the aggregated (i.e. mean) ratings can be considered as being credible representations of the respondents' individual agreement with each of the statements on homeowners' perceptions of benefits of PLFRA measures. The calculated rWG value for each of the statements is shown in Table 3.

Typically, rWG values $\geq 0.70$ is considered as evidence of significant agreement. Cohen et al. [44], however, found that rWG values vary considerably as a function of group size and number of response items and thus implying that the conventional value of 0.70 may be a reasonable cut-off value for significant agreement with some configurations of group sizes and number of response items. Therefore, following the recommendation by Cohen et al. [44], the rWG values for significant agreement were thus estimated based on a sample size of 280 and a number of response items of 5 (i.e. the five-point scale). Based on 10,000 simulation runs, rWG values of $0.06,0.08$ and 0.11 are the $90 \%, 95 \%$ and $99 \%$ confidence interval estimates, respectively. An rWG value $>0.11$ is thus evidence of significant agreement at $p<0.01$. From Table 3, it is evident that all the rWG values for each of the statements exceed 0.11 ; therefore,

Table 3: Descriptive statistics and inter-rater agreement indices for benefits of PLFRA measures.

\begin{tabular}{lcccccccc}
\hline $\begin{array}{l}\text { Intangible benefits of } \\
\text { PLFRA measures }\end{array}$ & Mean* & $\begin{array}{c}\text { Std. } \\
\text { dev. }\end{array}$ & $\begin{array}{c}\text { Std. } \\
\text { error }\end{array}$ & Median & Mode & Min & Max & rWG** \\
\hline $\begin{array}{l}\text { Adapting can reduce } \\
\text { worrying }\end{array}$ & 4.00 & 0.91 & 0.05 & 4.00 & 4.00 & 1 & 5 & 0.59 \\
$\begin{array}{l}\text { Adapting can reduce } \\
\text { stress of dealing with } \\
\text { builders }\end{array}$ & 3.94 & 0.91 & 0.05 & 4.00 & 4.00 & 1 & 5 & 0.59 \\
$\begin{array}{l}\text { Adapting can reduce } \\
\text { health effect }\end{array}$ & 3.75 & 0.97 & 0.06 & 4.00 & 4.00 & 1 & 5 & 0.53 \\
$\begin{array}{l}\text { Adapting can maintain } \\
\text { house value }\end{array}$ & 3.61 & 1.14 & 0.07 & 4.00 & 4.00 & 1 & 5 & 0.35 \\
$\begin{array}{l}\text { Adapting can reduce } \\
\text { strain between family } \\
\begin{array}{l}\text { Adapting can increase } \\
\text { community cohesion }\end{array}\end{array}$ & 3.61 & 0.95 & 0.06 & 4.00 & 4.00 & 1 & 5 & 0.55 \\
$\begin{array}{l}\text { Adapting can reduce } \\
\text { insurance premium/cost }\end{array}$ & 3.41 & 0.93 & 0.06 & 4.00 & 3.00 & 1 & 5 & 0.57 \\
\hline
\end{tabular}

* Mean ratings are based on a five-point scale $(1=$ strongly disagree, $2=$ disagree, 3 = uncertain, 4 = agree, $5=$ strongly agree).

**rWG is the single-item inter-rater agreement index. rWG indices are based on a uniform null distribution. Based on 10,000 simulation runs, rWG values of 0.06, 0.08 and 0.11 are $90 \%, 95 \%$ and $99 \%$ confidence interval estimates, respectively, for group size of 280 and 5 response options (i.e. five-point scale). Hence, $r W G$ values $>0.11$ are evidence of significant agreement at $p<0.01$ (99\% confidence level). 
they can be interpreted with confidence. From the result presented in Table 3, it can be inferred that there is significant agreement among the respondents on the potential benefits of PLFRA measures because of higher value of rWG obtained from the analysis. The mean ratings are, therefore, credible representations of the respondents' assessments. However, the result shows that respondents are uncertain if adapting properties can reduce insurance premiums (mean rating, 3.41).

\subsubsection{Analysis of influencing factors on the adoption of PLFRA measures}

For each of the statements, the ratings by the respondents ranged from 1 (strongly disagree) to 5 (strongly agree). The aggregated ratings by individual respondents (mean ratings) indicate that knowledge of frequency of flooding can encourage adapting property with a mean rating of 4.02 (with std dev. $=0.83$ ). It was perceived by most respondents that it is not the responsibility of the insurer to adapt properties against flood risk with a mean rating of 2.39 (with std dev. =1.02). This means that there is significant agreement among the respondents on the factors, which have the potential to influence decision making on investing in PLFRA measures. This level of agreement can be linked to the fact that all the respondents had previous flood experience, in which case their judgement can be said to be influenced by the experience they had during the flood event. Furthermore, their flood experiences may act as a catalyst to inform their desire to seek solution to flooding problems.

From Table 4, it can be interpreted that the first three statements were generally agreed by respondents as having the potential to influence the adoption of PLFRA measures, the next four statements fall within the scale of 'uncertain'.

From the results presented in Table 4, it can be inferred that there is general consensus that knowledge of frequency of flooding and the expected flood damage can encourage adapting property to flood risk. It can be seen that the mean rating for those who are in favour of adapting their properties to flood risk is 3.76 , which means that there is significant level of agreement among respondents in favour of adapting properties to flood risk; however, this has not resulted in action being taken by the respondents as shown in Table 2 that fewer people actually took any action in adapting their properties. This shows that awareness of the risk and solution do not necessarily lead to action being taking. This means that there are other factors, which affect respondents' ability to act.

Respondents were uncertain as to whether it is possible to prevent flood damage to properties, and it can be concluded here that more needs to be done with regard to publishing evidence of properties that have benefited from adaptation measures either under the DEFRA pilot grant scheme [37] or an insurance company's pilot scheme [45]. Evidencing these benefits to floodplain residents can serve as yardstick/measuring tool for them to decide on implementing adaptation measures. There is a general uncertainty level among respondents on the affordability of the cost of adaptation measures as shown in Table 4. Furthermore, respondents are still uncertain who is responsible for protecting properties against flooding, for instance, one of the respondents stated that:

... Why should I pay to protect my property? What is our Government doing? It is the job of my Local Authority to make sure that the drainage was clear of debris, if this has been done, we would not have suffered what we suffered in 2007 (Respondent).

Some of the respondents were uncertain as to whether adapting properties to flood risk is a waste of money or not, for instance, one of the respondents stated that:

... no matter what you do flood water will still get into your property, why then do you have to do anything when you will end up ripping them off later?" (Respondent). 
Table 4: Descriptive statistics and inter-rater agreement indices for factors that can influence implementation of PLFRA measures.

\begin{tabular}{lcccccccc}
$\begin{array}{l}\text { Influencing factors for } \\
\text { the adoption of PLFRA } \\
\text { measures }\end{array}$ & Mean* & $\begin{array}{l}\text { Std. } \\
\text { dev. }\end{array}$ & $\begin{array}{c}\text { Std. } \\
\text { error }\end{array}$ & Median & Mode & Min & Max & rWG** \\
\hline $\begin{array}{l}\text { Knowledge of frequency } \\
\text { of flooding can encourage } \\
\text { adapting property }\end{array}$ & 4.02 & 0.83 & 0.045 & 4.00 & 4.00 & 1 & 5 & 0.66 \\
$\begin{array}{l}\text { Knowledge of expected } \\
\text { flood damage can } \\
\text { encourage adapting }\end{array}$ & 3.95 & 0.87 & 0.05 & 4.00 & 4.00 & 1 & 5 & 0.62 \\
$\begin{array}{l}\text { property } \\
\text { Favour of adapting } \\
\text { property to flood risk }\end{array}$ & 3.76 & 0.93 & 0.06 & 4.00 & 4.00 & 1 & 5 & 0.59 \\
$\begin{array}{l}\text { It is not possible to } \\
\text { prevent flood damage to } \\
\text { property }\end{array}$ & 2.94 & 1.08 & 0.07 & 3.00 & 3.00 & 1 & 5 & 0.41 \\
$\begin{array}{l}\text { I cannot afford the cost } \\
\text { of adaptation measures }\end{array}$ & 2.71 & 1.08 & 0.07 & 3.00 & 3.00 & 1 & 5 & 0.42 \\
$\begin{array}{l}\text { It is my responsibility to } \\
\text { adapt my property to } \\
\text { flood risk }\end{array}$ & 2.56 & 1.06 & 0.06 & 2.00 & 2.00 & 1 & 5 & 0.44 \\
$\begin{array}{l}\text { Adapting property is } \\
\text { a waste of money }\end{array}$ & 2.50 & 0.98 & 0.06 & 2.00 & 2.00 & 1 & 5 & 0.52 \\
$\begin{array}{l}\text { Responsibility of insurer } \\
\text { to adapt my property } \\
\text { because I am fully } \\
\text { insured }\end{array}$ & 2.39 & 1.02 & 0.06 & 2.00 & 2.00 & 1 & 5 & 0.48 \\
\hline
\end{tabular}

*Mean ratings are based on a five-point scale $(1=$ strongly disagree, $2=$ disagree, 3 = uncertain, 4 = agree, $5=$ strongly agree).

**WW is the single-item inter-rater agreement index. rWG indices are based on a uniform null distribution. Based on 10,000 simulation runs, rWG values of 0.06, 0.08 and 0.11 are the $90 \%, 95 \%$ and $99 \%$ confidence interval estimates, respectively, for group size of 280 and 5 response options (i.e. five-point scale). Hence, $r W G$ values $>0.11$ are evidence of significant agreement at $p<0.01(99 \%$ confidence level).

Statements such as the above show that their belief in the effectiveness of available adaptation measures is very limited. Although the degree of effectiveness of resilience or resistance measures varies greatly and depends on various factors, such as the ability to deploy the measures as and when necessary, maintenance issues and the ability of the neighbouring property to be able to adopt similar measures (especially for terraced and semi-detached properties). Failure to achieve most of these factors would eventually limit the effectiveness of the measures, thereby sending wrong messages to those who may be thinking of implementing similar measures in their properties. 
As it can be interpreted that there is a consensus among respondents that it is not the responsibility of the insurer to adapt their properties to flood risk despite their fully insured status, this is indicated with the mean rating of 2.39. Further analysis of the results show that $24 \%$ of respondents were uncertain as to where the responsibility should be placed. Some $13 \%$ of respondents were of the opinion that it is the responsibility of the insurer to adapt properties to flood risk. These findings are consistent with earlier similar studies [46,47].

\section{DISCUSSION}

In view of the findings presented earlier, several key lessons can be learned in relation to the perception of homeowners on the benefits of PLFRA measures. It can be seen that there was greatest consensus among respondents on the potential benefits of adaptation measures. Benefits such as a reduction in worrying, stress of dealing with builders and reduction of other health-related impact of flooding were ranked highly by respondents. This is not surprising because the majority of the respondents had first-hand experience of flood damage to their properties in 2007 , so they were able to fully assess how the flood event impacted on their households. Research has shown that the effect of flooding on house value is usually only a temporary nature [48]; however, the results of the analysis (as shown in Table 3) indicate that respondents perceived that adapting properties to flood risk has the potential to maintain house values. The high level of uncertainty recorded in the survey on the potential benefits of adaptation measures to reduce insurance premiums is not surprising because currently insurance companies in England and Wales are not generally incentivising homeowners through reductions in premiums or excesses, despite calls from different authors such as Joseph et al. [21], Thurston et al. [8] and Wedawatta et al. [49]. However, insurers can play a positive role in property adaptation process by assisting individuals to understand the risks they face and promoting adaptation investments. Property insurance can encourage adaptation only if premium prices first reflect the risk to which properties are actually exposed, i.e. risk-based pricing. Then, an insurer can incentivise measures taken to reduce risk by correspondingly lowering insurance premiums. For an insurer, this could have the direct advantage of lowering the unpredictability (frequency and severity) of flood claims.

Knowledge of the frequency of flooding and expected flood damage are the two factors with highest level of agreement among respondents. Dhonau et al. [50] asserted that the awareness of a potential danger has the prospect to instigate the desire to take action to prevent such danger. However, the awareness of flood risk is just one step; taking action to reduce its impact on households goes beyond awareness. The Environment Agency have produced hazard maps, which can be used to assess the potential flood risk being faced by a particular region, but people need specific information about their individual risk. However, the knowledge of flood risk may not necessarily encourage action unless the homeowner "owns" the risk. Fully insured homeowners may be seen to have offset their risk through insurance unless they understand and appreciate the intangible benefits of adopting PLFRA measures.

There is a greater consensus among respondents that they are in favour of adapting their properties to flood risk, that is they have the desire to adapt but with some issues around ownership of the flood risk mitigation at household level. If this is the case, the next question to address is why are homeowners not adapting their properties to flood risk when they appear to be in favour of it? This question can be answered by looking at the level of uncertainty among respondents with regard to the effectiveness of adaptation measures to prevent flood damage (see Table 4); this means that there is still issues around the lack of belief in the 
ability of resistance/resilience measures to prevent flooding. This can be seen as one of the main reasons why the level of adopting PLFRA measures is low despite the level of awareness of the benefits of the measures. Furthermore, there was mild disagreement among respondents on the issue of affordability of the cost of the measures. Other factors with high level of uncertainty are "whether it is the responsibility of the homeowners to adapt properties to flood risk or not and the fact that respondents are not certain whether it is a waste of money or not'. These results concur with the previous research on barriers to adaptation measures [17]. Financial barriers are seen as one of the reasons why at-risk homeowners are not taking up adaptation measures despite the fact that they are in favour of the measures. This means that, if a government grant is made available to the wider at-risk population, there is potential for an increase in take-up of adaptation measures, as evidence in JBA [37] report, which shows approximately $93 \%$ participation due to the fact that no financial contributions were required from the participants.

Respondents were uncertain as to who is responsible for protecting their homes against flood risk. However, there was general agreement among respondents that insurers are not responsible for adapting properties to flood risk. Therefore, to succeed in generating change it is important for at-risk populations to be aware of the limit of the responsibilities of others. Currently, it appears that most at-risk populations are receiving conflicting messages about risk and most will choose to hope for others to take the responsibility, and hence, the need to provide clear information on who is responsible for doing what with regard to flood risk management at household levels.

\section{CONCLUSIONS}

This study has shed more light on the key issues and factors, which affect flood-affected homeowner's perceptions towards investing in PLFRA measures. There is consensus among homeowners that implementing adaptation measures have the potential to reduce intangible impacts of flooding on households. There exists a high level of uncertainty as to the financial benefits of investing in such measures. This suggests that financial incentivises have the potential to lead to higher uptake of PLFRA measures. This was evidenced in the recently completed government property-level flood protection grant scheme, which showed that a high number of homeowners participated because they were not required to contribute financially towards the installation of the measures.

There is a lack of ownership of flood risk among the participants in this study. There is a potential to improve this, if insurers change their premium setting procedures. Furthermore, there is a need for government to communicate more clearly about the limit of their responsibilities. For instance, recent flood events (December 2013/January 2014) witnessed the UK government providing grants of $£ 5,000$ (maximum) to homeowners who were affected by the flood event. This action may have added to the confusion of who should be responsible for flood mitigation at household levels. It is hoped that new developments in flood insurance for England (i.e. the new Flood Re scheme) can be used to add clarity.

\section{REFERENCES}

[1] Environment Agency, Flooding in England: A National Assessment of Flood Risk, Environment Agency: Bristol, 2009.

[2] DEFRA, Climate Change Risk Assessment for the Flood and Coastal Erosion Sector, DEFRA: London, 2012.

[3] Soetanto, R., Proverbs, D., Lamond, J. \& Samwinga, V., Residential properties in England and Wales: an evaluation of repair strategies towards attaining flood resilience. 
Hazards and the Built Environment: Attaining Built-in Resilience, ed. L. Bosher, Routledge Taylor \& Francis Group: London and New York, pp. 124-149, 2008.

[4] Neal, R., Bell, S. \& Wilby, J., Emergent disaster response during the June 2007 floods in Kingston upon Hull, UK. Journal of Flood Risk Management, 4(3), pp. 260-269, 2011. doi: http://dx.doi.org/10.1111/j.1753-318x.2011.01110.x

[5] Evans, E.P., Ashley, R., Hall, J., Penning-Rowsell, E., Sayers, P., Thorne, C. R. \& Watkinson, A., Foresight. Future Flooding, vols 1 and 2, London, UK: Office of Science and Technology, 2004.

[6] Kazmierczak, A. \& Bichard, E., Investigating homeowners' interest in property - level flood protection. International Journal of Disaster Resilience in the Built Environment, 1(2), pp. 157-172, 2010. doi: http://dx.doi.org/10.1108/17595901011056622

[7] Joseph, R., Proverbs, D., Lamond, J. \& Wassell, P., An analysis of the costs of resilient reinstatement of flood affected properties: a case study of the 2009 flood event in Cockermouth. Structural Survey, 9(4), pp. 279-293, 2011.

[8] Thurston, N., Finlinson, B., Breakspear, R., Williams, N., Shaw, J. \& Chatterton, J., Developing the Evidence Base for Flood Resistance and Resilience, Joint Defra/EA Flood and Coastal Erosion Risk Management R\&D. DEFRA: London, 2008.

[9] Wassell, P., Ayton-Robinson, R., Robinson, D., Joseph, R., Hack, K., Butler, D., Salkeld, I. \& Twomey, J., Resilient Reinstatement: The Costs of Flood Resilient Reinstatement of Domestic Properties. Association of British Insurers: London, 2009.

[10] IPCC, Managing the Risks of Extreme Events and Disasters to Advance Climate Change Adaptation, A special report of working groups I and II of the Intergovernmental Panel on Climate Change, Cambridge University Press: Cambridge, 2012.

[11] Lamond, J.E. \& Proverbs, D.G., Resilience to flooding: lessons from international comparison. Urban Design and Planning, 162(DP2), pp. 63-70, 2009. doi: http:// dx.doi.org/10.1680/udap.2009.162.2.63

[12] Mark, E.K., Building human resilience: the role of public health preparedness and response as an adaptation to climate change. American Journal of Preventive Medicine, 35(5), pp. 508-516, 2008. doi: http://dx.doi.org/10.1016/j.amepre.2008.08.022

[13] Kreibich, H., Thieken, A.H., Petrow, T., Müller, M. \& Merz, B., Flood loss reduction of private households due to building precautionary measures - lessons learned from the Elbe flood in August 2002. Natural Hazards and Earth System Sciences, 5, pp. 117-126, 2005. doi: http://dx.doi.org/10.5194/nhess-5-117-2005

[14] Crichton, D., Flood Risk and Insurance in England and Wales: Are There Lessons to be Learned From Scotland? Benfield Hazard Research Centre. London: University College London, 2005.

[15] DEFRA, Draft Flood and Water Management Bill, Department for Environment, Food and Rural Affairs: London, 2009.

[16] Lamond, J. \& Proverbs, D., The long term financial implications of flooding and flood risk to homeowners. 44th Defra Conference in Flood and Coastal Risk Management (FCRM09), Telford, 2009.

[17] Proverbs, D. \& Lamond, J., The barriers to resilient reinstatement of flood damaged homes. Proceedings of 4th International i-Rec Conference-Building Resilience: Achieving Effective Post-disaster Reconstruction, Christchurch, New Zealand, 2008.

[18] Pitt, M., The Pitt Review - Learning Lessons from the 2007 Floods. H M Government Cabinet Office: London, 2008.

[19] Wallingford, H.R., Development of Spatial Indicators to Monitor Changes in Exposure and Vulnerability to Flooding and the Uptake of Adaptation Actions to Manage Flood 
Risk in England. London: Committee on Climate Change Adaptation Sub-Committee, 2012.

[20] Bubeck, P., Botzen, W.J.W., Suu, L.T.T. \& Aerts, J.C.J.H., Do flood risk perceptions provide useful insights for flood risk management? Findings from central Vietnam. Journal of Flood Risk Management, 5(4), pp. 295-302, 2012. doi: http://dx.doi.org/10.1111/ j.1753-318x.2012.01151.x

[21] Joseph, R., Proverbs, D., Lamond, J. \& Wassell, P., A critical synthesis of the intangible impacts of flooding on households. International Conference in Building Resilience: Interdisciplinary Approaches to Disaster Risk Reduction and the Development of Sustainable Communities, Sri Lanka, 2011.

[22] DEFRA, Flood Risk and Insurance: A Roadmap to 2013 and Beyond. Final Report of the Flood Insurance Working Groups. DEFRA: London, 2011.

[23] Reacher, M., Mckenzie, K., Lane, C., Nichols, T., Iversen, A., Hepple, P., Walter, T., Laxton, C. \& Simpson, J., Health impacts of flooding in Lewes: a comparison of reported gastrointestinal and other illness and mental health in flooded and non-flooded households. Communicable Disease and Public Health, 7(1), pp. 1-8, 2004.

[24] Warren, R., Tindle, A. \& Whalley, R., Flood resilient repairs and resistance measures: qualitative and quantitative research to examine the views of consumers. ABI Research Paper No. 28, Association of British Insurers, London, 2011.

[25] Met Office 2007, June 2007 - Record Rainfall. http://www.metoffice.gov.uk/climate/uk/ interesting/june2007/index.html, 2007 [accessed 03/05/2013].

[26] Stuart-Menteth, A., U.K. Summer 2007 Floods, Risk Management Solutions, Inc.: Newark, USA, 2007.

[27] Chatterton, J., Viavattene, C., Morris, J., Penning-Rowsell, E. \& Tapsell, S. M., Delivering benefits through evidence: The costs of the summer 2007 floods in England, Environment Agency: Bristol, 2010.

[28] Gray, D., Doing Research in the Real World, Sage, London, 2004.

[29] Dillman, D.A., Mail and Internet Surveys: The Tailored Design Method, Wiley, 2007.

[30] Creswell, J.W. (ed.), Research Design: Qualitative, Quantitative, and Mixed Method Approaches, Sage Publication: Thousand Oaks, CA, 2003.

[31] Creswell, J.W., Research Design: Qualitative, Quantitative, and Mixed Methods Approaches, 3rd edn., Sage: London, 2009.

[32] Soetanto, R., Proverbs, D.G. \& Nicholas, J., Assessment of flood damage to domestic properties: surveyors' perceptions of flood characteristics. Proceedings of the RICS Foundation Construction and Building Research Conference, Nottingham Trent University, 5-6 September, pp. 154-168, 2002.

[33] Samwinga, V., Homeowner satisfaction and service quality in the repair of UK flooddamaged domestic property, PhD Thesis, University of Wolverhampton, 2009.

[34] Sutrisna, M., Developing a knowledge based system for the valuation of variations in civil engineering works, $P h D$ Thesis, University of Wolverhampton, 2004.

[35] Whitmarsh, L., Are flood victims more concerned about climate change than other people? The role of direct experience in risk perception and behavioural response. Journal of Risk Research, 11(3), pp. 351-374, 2008. doi: http://dx.doi. org/10.1080/13669870701552235

[36] Harries, T., Householder responses to flood risk. The consequences of the search for ontological security, PhD Thesis, Middlesex University, 2007.

[37] JBA, Evaluation of the Defra Property-level Flood Protection Scheme, Environment Agency: Bristol, 2012. 
[38] Tinsley, H.E. \& Weiss, D.J., Interrater reliability and agreement of subjective judgments. Journal of Counseling Psychology, 22(4), pp. 358-374, 1975. doi: http://dx.doi. org/10.1037/h0076640

[39] Manu, P.A., An investigation into the accident causal influence of construction project features, PhD Thesis, University of Wolverhampton, 2012.

[40] Bliese, P.D., Within group agreement, non-independence and reliability. Multilevel theory, research, and methods in organizations: Foundations, extensions, and new directions, eds. K.J. Klein \& S.W.J. Kozlowski, Jossey-Bass: San Francisco, 2000.

[41] Tuuli, M.M., Empowerment and control dynamics in project teams: A multi-level examination of antecedents, job performance, and consequences, $P h D$ Thesis, University of Hong Kong, 2009.

[42] Anvuur, A.M. \& Kumaraswamy, M., Promises, pitfalls and shortfalls of the guaranteed maximum price approach: a comparative case study. Proceedings of 26th Annual ARCOM Conference, Association of Researchers in Construction Management, 6-8 September, Leeds, UK, pp. 1079-1088.

[43] James, L.R., Demaree, R.G. \& Wolf, G., Estimating within-group interrater reliability with and without response bias. Journal of Applied Psychology, 69(1), pp. 85-98, 1984. doi: http://dx.doi.org/10.1037/0021-9010.69.1.85

[44] Cohen, A., Doveh, E. \& Eick, U., Statistical properties of the rwg(j) index of agreement. Psychological Methods, 6(3), pp. 297-310, 2001. doi: http://dx.doi.org/10.1037/1082989x.6.3.297

[45] Norwich Union, UK Householders Fear Flood Risk is Increasing, available at http:// www.norwichunion.com/media-centre/story/2327/uk-householders-fear-flood-risk-isincreasing/, 2005 (accessed 29th December).

[46] Werritty, A., Houston, D., Ball, T., Tavendale, A. \& Black, A., Exploring the social impacts of flood risk and flooding in Scotland. Scottish Executive Social Research, 2007.

[47] Owusu, S., Wright, G. \& Arthur, S., Public attitudes towards flooding and property level flood protection measures. International Conference on Flood Resilience; Experiences in Asia and Europe, 5-7th September 2013, Exeter: United Kingdom, 2013.

[48] Lamond, J.E., The impact of flooding on the value of residential property in the UK. PhD Thesis, University of Wolverhampton, 2008.

[49] Wedawatta, G., Ingirige, B. \& Proverbs, D., Small- and medium-sized enterprises and flood impacts: the case of the 2009 flood event in Cockermouth. Journal of Flood Risk Management, pp. 1-12, 2013.

[50] Dhonau, M., Sherwood-Rogers, J. \& Burton, R., Homeowners Guide to Flood Resilience A living Document, Lichfield: RAB Consultants, 2011.

[51] Brent, R.J., Cost-Benefit Analysis and Health Care Evaluations, Edward Elgar Publishing Ltd: Cheltenham, 2003. 